\title{
Solitary pyogenic granuloma of the small bowel as the cause of obscure gastrointestinal bleeding
}

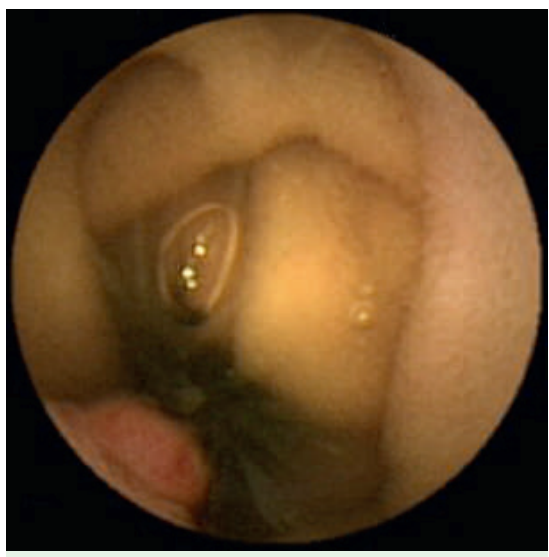

Fig. 1 Capsule endoscopy: hyperemic smallbowel polyp (pyogenic granuloma).

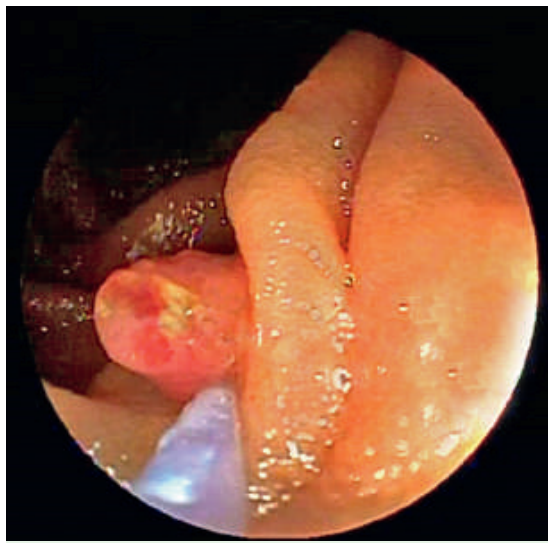

Fig. 2 Hyperemic small-bowel sessile polyp confirmed by double-balloon enteroscopy.

Pyogenic granuloma is rare in the gastrointestinal tract and mostly occurs on the skin and in the oral cavity [1]. This type of lesion usually bleeds and is responsible for chronic anemia and gastrointestinal bleeding of unknown origin [2-5]. Here we report on a case of pyogenic granuloma in the jejunum diagnosed by capsule endoscopy and treated by snare polypectomy using double-balloon enteroscopy. A 55-year-old white man with no previous medical history presented with an 8-month history of anemia and a positive fecal occult blood test. His only complaint was weakness. He denied melena or hematochezia. Laboratory data were as follows: hemoglobin level, $9.9 \mathrm{~g} / \mathrm{dL}$ (normal range, $12.8-16.5 \mathrm{~g} / \mathrm{dL}$ ); hematocrit level,
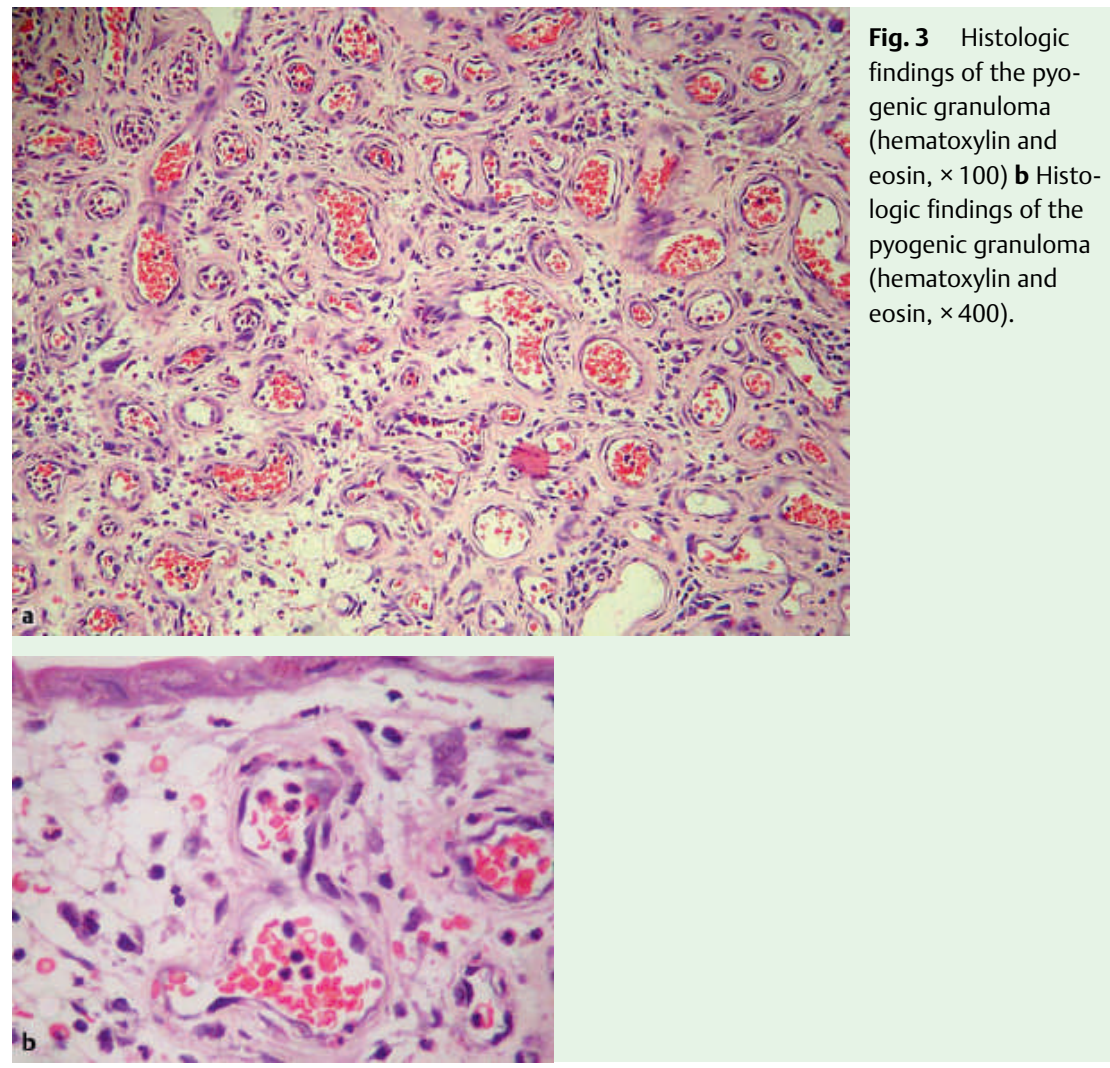

$31 \%$ (normal range, $37 \%-52 \%$ ); red blood cell count, $371 \times 10^{4} / \mathrm{mm}^{3}$ (normal, $\left.>420 \times 10^{4} / \mathrm{mm}^{3}\right)$; and platelet count,

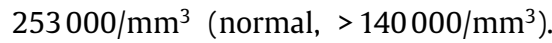
During this period, he underwent upper gastrointestinal endoscopy, which revealed no potential bleeding lesion, and colonoscopy, which revealed sigmoid diverticulum and no signs of bleeding. Computed tomography scan of the abdomen was normal. Capsule endoscopy revealed a small hyperemic sessile polypoid lesion in the jejunum without bleeding (๑ Fig. 1).

The patient underwent double-balloon endoscopy, which confirmed the findings of capsule endoscopy ( $\bullet$ Fig. 2) and permitted endoscopic diathermy snare polypectomy with no complications.

The resected specimen was $4 \mathrm{~mm}$ in diameter. Histologic findings revealed proliferation and lobular arrangement of capillary vessels, swelling of the endothelial cells within edematous stroma, and mixed inflammatory cell infiltration
(๑ Fig. 3); these findings were compatible with pyogenic granuloma.

There was no recurrence of gastrointestinal bleeding 10 months after the endoscopic resection.

In conclusion, pyogenic granulomas of the small bowel should be considered as rare lesions that cause obscure gastrointestinal bleeding. With the advent of double-balloon enteroscopy, these lesions can be safely treated by endoscopic means.

Endoscopy_UCTN_Code_CCL_1AC_2AD 
R. Kuga, C. K. Furuya Jr, S. N. Fylyk, P. Sakai

Gastrointestinal Endoscopy Unit, Department of Gastroenterology, Sao Paulo University Medical School, Sao Paulo, Brazil

\section{References}

1 Enzinger FM, Weiss SW. Benign tumor and tumor-like lesion of blood vessels. In: Enzinger FM, Weiss SW, eds. Soft tissue tumors. 4th edn. St. Louis Mosby Company; 2001: $864-865$

2 Shirakawa K, Nakamura T, Endo $M$ et al. Pyogenic granuloma of the small intestine. Gastrointest Endosc 2007; 66: 827-828

3 Kim YS, Chun HJ, Jeen YT et al. Small bowel capillary hemangioma. Gastrointest Endosc 2004; 60: 599

4 van Eeden S, Offerhaus GJ, Morsink FH et al. Pyogenic granuloma: an unrecognized cause of gastrointestinal bleeding. Virchows Arch 2004; 444: 590-593

5 Wardi J, Shahmurov M, Czerniak A, Avni Y. Clinical challenges and images in GI. Capillary hemangioma of small intestine [ 2084]. Gastroenterology 2007; 132: 1656
Bibliography

DOI $10.1055 / \mathrm{s}-0029-1214428$

Endoscopy 2009; 41: E76-E77

(c) Georg Thieme Verlag KG Stuttgart · New York . ISSN 0013-726X

\section{Corresponding author}

\section{R. Kuga MD}

Rua Cincinato Braga

37-cj. 12

01333-011

São Paulo - SP

Brazil

Fax: +55-11-32850026

rogeriokuga@yahoo.com.br 